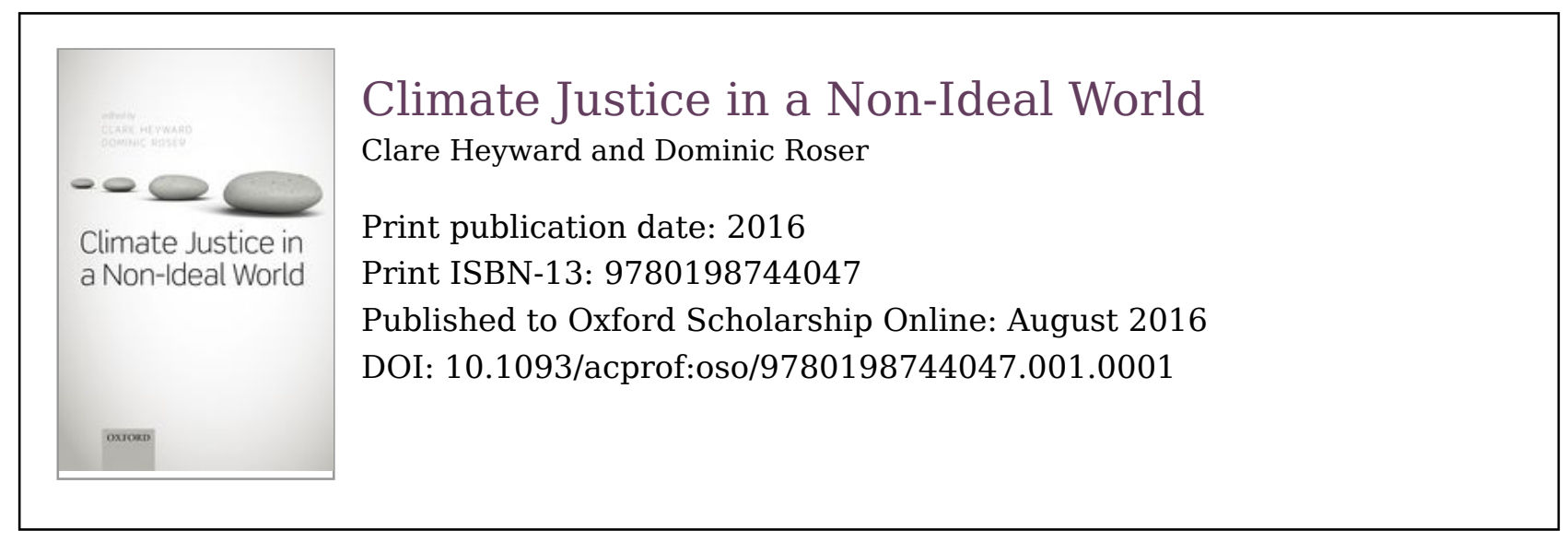

\title{
Aristotle on the Ethics of Communicating Climate Change
}

\author{
Michael Lamb \\ Melissa Lane
}

DOI:10.1093/acprof:oso/9780198744047.003.0012

\begin{abstract}
Keywords
The field of climate change communication (CCC) has recently emerged to address the gap between scientific knowledge of climate change and public motivation to respond. Psychologists in this field have offered helpful strategies for improving the effectiveness of CCC, but their empirical research tends to neglect the ethics of CCC. Philosophers have been more attentive to ethical communication, but they tend to focus on its cognitive dimensions and minimize the affective and social dimensions that contribute to effectiveness. As a result, studies that address ethics and effectiveness in tandem are lacking. This chapter fills this gap by recovering insights from Aristotle's Rhetoric. By situating all communication within an ethical relationship between speaker and auditor, emphasizing the agency and judgement of auditors, and highlighting ways to build trust, Aristotle offers an art of rhetoric that can help climate scientists communicate both ethically and effectively.
\end{abstract}

Keywords: Aristotle, climate change communication, rhetoric, effectiveness, ethics, trust

11.1 Communicating Climate Change in Non-Ideal Circumstances If justice requires urgent and effective action to address climate change, current policies fall radically short of what it demands. One reason for this is that many citizens and policymakers lack the motivation to act urgently in response to environmental threats. Contrary to what many assume, this motivation deficit is not caused simply by a lack of knowledge. Studies suggest that increased 
knowledge about climate change does not necessarily translate into increased action or concern. Rather, practical responses are conditioned by a range of other factors, including a lack of 'trust' in scientists (Malka, Krosnick, and Langer 2009: 243; Swim et al. 2009: 126; Fiske and Dupree 2014). This lack of trust is itself a non-ideal feature of the current world.

Much work in the emerging field of 'climate change communication' (CCC) aims to address this deficit by exploring how climate scientists and advocates can communicate scientific knowledge effectively to motivate action and inspire trust. ${ }^{1}$ In analysing what contributes to trust of scientists, scholars have identified the affective dimension of trust in a communicator's intention to be as important as their perceived intellectual competence (Fiske and Dupree 2014). In this way, psychological research has helpfully highlighted the central role that values, emotions, and trust play in effective communication. Yet, for the most part, discussions of trust among psychologists and social scientists have lacked a detailed normative framework. If we turn to (p.230) normative research in moral and political philosophy, however, we find a lacuna exactly where we seek guidance. Ethicists studying scientific communication have tended to limit their attention to the cognitive dimensions of trust and have downplayed the affective dimensions of communicative relationships. Studies that consider ethics and effectiveness in tandem-and as potentially related-are sorely lacking.

This chapter addresses this gap by recovering insights from Aristotle, whose art of rhetoric connects effectiveness and ethics in a common root. Rather than advocating the kind of manipulative communication often associated with rhetoric today, Aristotle conceives rhetoric as what Danielle Allen describes as an 'art of trust production', one disciplined by a concern for truth and directed toward the deliberation and judgement of the audience (Allen 2004: 141). By integrating Aristotle's art of trust production with insights from cognitive psychology and environmental communication, we seek to provide guidance to scientists involved in communicating climate change. ${ }^{2}$ We do so on two assumptions: first, that the CCC goal of a better informed and motivated public is worth achieving, however causally relevant its role in bringing about political, economic, and environmental reforms turns out to be; and second, that ethical communication is an important requirement in a democracy, where citizens are expected to be able to deliberate on policy questions and express their understandings in their civic roles, yet where some possess specialized knowledge that others lack. ${ }^{3}$ We do not presume that better communication alone can resolve the climate challenge, but insofar as effective communication is one part of the solution in a democratic society where political equality must comport with varying levels of epistemic inequality, our chapter aims to make this communication credible and ethically sound. 
The argument proceeds in three parts. Section 11.2 examines recent developments in the field of 'persuasive communication' and evaluates current psychological and philosophical research. Section 11.3 considers why Aristotle's Rhetoric is a relevant resource for contemporary reflection, and Section 11.4 identifies a specific practical challenge to CCC in non-ideal circumstances-the problem of 'cold competence'-and applies Aristotle's insights on character, emotion, and trust to show how communicators can avoid or alleviate it. (p. 231)

\subsection{Inverted Blind Spots: Persuasive Communication in Psychology and Philosophy}

In 2009, the American Psychological Association (APA) published a report outlining contributions that psychology can make to the study of climate change (Swim et al. 2009). Given threats that climate change poses to human wellbeing, the APA suggested that it is ethically appropriate for psychologists to address 'arguably one of the most pressing issues facing our planet and its inhabitants', in part by providing insight into 'communication and diffusion techniques and methods' that can be used to change environmental behaviour (Swim et al. 2009: 6, 137). Informed by this research and charged by the APA's ethical imperative, psychologists have been leading the efforts to guide and improve CCC.

Scholars' attention to the psychology of CCC has been immensely valuable, particularly in highlighting the salience of 'affect, values and worldviews' in successful communication (quoting from Weber and Stern 2011: 320; see also, e.g., Leiserowitz 2006, 2007; Lorenzoni and Pidgeon 2006; Chess and Johnson 2007; Dunwoody 2007; Harré 2012). ${ }^{4}$ Recognition of these factors derives from social psychologists' identification of two 'fundamental dimensions' of 'social judgement', broadly labelled as 'competence' on the one hand, and 'warmth' on the other. ${ }^{5}$ Trust-the willingness to accept the communication as intended-is a function of both. For a speaker to be trusted, it is not enough for her to be judged to communicate with competence: if her 'warmth' is not judged adequate, her communication may still be distrusted.

The salience of warmth, along with values and affect, has led many psychologists to recommend revised strategies for communicative public action. In The Psychology of Climate Change Communication, for example, the Center for Research on Environmental Decisions (CRED) draws on psychological research to recommend strategies to 'communicate effectively' and 'frame' debates to make messages more persuasive (CRED 2009: 2, 6). In keeping with the APA framework, this guide specifies that the intention of such framing strategies is not to deceive or manipulate people, but to make credible science more accessible to the public' (CRED 2009: 6). In particular, the guide warns against hiding uncertainties or overusing emotional appeals that 'may backfire down the 
road, causing negative consequences that often prove quite difficult to reverse' (CRED 2009: 20).

(p.232) We affirm the aim to increase communicative effectiveness while avoiding manipulation and distrust. Indeed, we believe that achieving this aim will be more likely and sustainable if empirical CCC research is evaluated in normative terms. 'Effectiveness,' after all, is itself a normative value: studies that prioritize 'effectiveness' as the value to be maximized or promoted are implicitly making assumptions about what constitutes 'good communication'. Engaging in detail with normative questions, however, has not yet been a major focus of CCC research. The APA report, for example, describes climate change as an 'interdisciplinary issue' and recommends that psychologists 'make connections to research from other social, engineering, and natural science fields,' but makes no mention of normative disciplines such as philosophy, ethics, or political theory (Swim et al. 2009: 160-2). Similarly, one of the most comprehensive volumes on CCC calls for increased 'multi- and interdisciplinary research on communication and social change,' but when the authors identify areas for future research, they focus almost exclusively on empirical research in the natural and social sciences (Moser and Dilling 2007b: 508-11). Strategic 'effectiveness' remains their primary 'evaluative yard stick' (Moser and Dilling 2007b: 511).

Our aim in this chapter is to propose ways of further articulating and specifying the ethical standards that such psychologically informed CCC strategies should meet. Since CCC is a form of persuasive communication, of what the ancient Greeks called 'rhetoric', CCC, like all persuasive communication, is potentially vulnerable to the classic forms of rhetorical misconduct: 'pandering' (which involves exploiting an audience's existing values, beliefs, and opinions to further one's own agenda), and 'manipulation' (which, on one understanding, involves attempting to change audiences' minds to advance one's own interests rather than enabling them to judge for themselves) (see Garsten 2006: 2, 5-7). Clearly, many scholars of CCC are committed to avoiding these dangers-for example, by explicitly warning communicators against being deceptive or untruthful (Leiserowitz 2007: 56; CRED 2009: 20). Nevertheless, we believe their success in communicating ethically would be enhanced by deeper engagement with normative research into the moral values that define legitimate communication, especially among free and equal citizens. The absence of such engagement leaves a potentially dangerous gap in which CCC experts risk being perceived as knowing what is best for their audiences and simply trying to persuade audiences to accept these predetermined conclusions. Such communicators could be perceived as exploiting their epistemic superiority to assume an unwarranted kind of arbitrary power over non-experts, treating their fellow citizens as passive subjects of manipulation rather than active, co-deliberating agents. Without further attention to appropriate ethical values and constraints, 
CCC risks being received as a set of strategic tools that can be manipulated for any purpose.

(p.233) If psychologists do turn to normative ethics, however, they are not yet likely to find ethical guidance that takes full account of the issues of affect and trust that they themselves have helpfully highlighted. Political theorists interested in environmental issues tend to neglect communication altogether, perhaps because of a broader distrust of rhetoric in modern political thought. While a number of political theorists have recently rehabilitated rhetoric's standing (Bickford 1996; Allen 2004; Garsten 2006), this research has not yet been applied to CCC.

Some philosophers, for their part, have been more attentive to the ethics of communication-though, as Jonathan Barnes has dryly observed, '[m]odern philosophy does not greatly occupy itself with rhetoric' (Barnes 1995: 259). Those few who do engage with it tend to emphasize the cognitive parameters of communication and downplay the affective and social dimensions of character, emotion, and trust. In Rethinking Informed Consent in Bioethics, for example, Neil Manson and Onora O'Neill (2007) devote several chapters to the relationship between communication, trust, and informed consent. Emphasizing that 'communicative acts presuppose the practical and cognitive commitments both of those who seek to communicate, and of those with whom they seek to communicate,' they offer a framework for the communicative relationship that goes beyond the one-off, one-way acts of messaging studied in much psychological research (Manson and O'Neill 2007: 54-5, 61-3). Yet, while Manson and O'Neill rightly recognize trust as an essential feature of their communicative model, they still tend to treat trust as primarily cognitive, suggesting that trust relies on mechanisms that 'combine informed with independent judgment' (176).

Meanwhile, philosophers and political theorists who attempt to define 'manipulation' - a definition that could address the lacuna we have noted among psychologists-have difficulty establishing exactly where to draw an appropriate line in the ethics of communication. ${ }^{6}$ Consider, for example, the approach taken by Robert E. Goodin (1980), who defines manipulation in terms that make it inherently an unethical use of power. According to Goodin, manipulation involves 'bending another's will' (Goodin 1980: 18). His eventual test for the concept sets out two questions as jointly necessary: '1. Is the interference deceptive? 2. Is the interference contrary to the putative will of those subject to it? Together, these two features define an instance of manipulation' (Goodin 1980: 35). This test may be usefully applied to the manipulation of actions in relation to which there are reasonable grounds for (p.234) attributing a coherent 'putative will'glossed by Goodin at one point as a 'pre-existing will' (Goodin 1980: 23). For example, there may be good reasons to hold that Carolyn would oppose the imposition of a gasoline or petrol tax, such that deceiving her to get her to 
support such a tax would count as manipulation. But now imagine a case of some kind of CCC to Carolyn, who (ex hypothesi) lacks knowledge about climate change and its potential implications for society and ecology. Setting aside the separate question of deceit, such communication might reasonably be expected to alter her 'pre-existing will' in relation to future proposals for action. Are we justified in attributing to Carolyn a 'putative will' that would now make her willing to accept a gasoline or petrol tax? Or does this assumption attribute too much, going too far in drawing on her behalf the implications for action of the CCC that she should be entitled to judge for herself? The counterfactual grip that we might have on the notion of someone's 'putative will' comes under strain as soon as the act in question is meant to provide them with information that would, if accepted, reorient their judgement of possible, advisable, or necessary actions. As a result, Goodin's philosophical test for manipulation does not address one of the fundamental ethical issues raised by communication, nor does it adequately recognize the role of audience judgement in distinguishing legitimate persuasion from unethical manipulation. We suggest below that Aristotle's perspective serves us better. In particular, Aristotle fuses rhetoric with moral psychology, ethics, and political science in a way that shows how persuasive communication can be both effective and ethical.

\subsection{Why Aristotle?}

Sceptics may wonder how a philosopher from the fourth century BCE can teach us anything about ethical communication, particularly since 'rhetoric' today is associated with manipulative or superficial speech, opposed to rational-and scientific-argument. Surprisingly, Aristotle's context has important similarities with our own context, where the important role of rhetoric is often misunderstood. ${ }^{7}$

Before Aristotle wrote his influential treatise, rhetoric in ancient Athens had a reputation like the one that plagues it today. The most prominent practitioners included 'sophists' and others who used rhetoric to ingratiate crowds and manipulate the masses, an abuse that led some Greek philosophers to reject rhetoric altogether. In Plato's Gorgias, for example, Socrates attacks (p.235) sophistic rhetoric as a form of 'flattery', a deceptive attempt to say whatever pleases the people (Plato 1997: 462c-6a). By Socrates's lights, rhetoricians are nothing but flatterers who falsely claim expertise and pander to attain power and prestige (Plato 1997: 459a-c, 462a-463d). ${ }^{8}$

Plato's critique in the Gorgias has striking resonance with contemporary suspicions of 'rhetoric' in CCC. While scholars such as Dan Kahan (2010) focus on making scientists' communication more persuasive, one social psychologist, Baruch Fischhoff, has concluded that any form of persuasive communication by scientists is too dangerous to be permissible (Fischhoff 2007). Like Socrates in Plato's Gorgias, Fischhoff treats persuasion as manipulative rhetoric-in-thepejorative, equating all 'persuasion' with a kind of 'public advocacy' that 'follows 
the norms of politics', where communicators avoid acknowledging uncertainties and selectively present evidence to persuade an audience (Fischhoff 2007: 7205). Bound by no constraints except political expediency, persuasive communication turns 'scientists into peddlers rather than arbiters of truth' (Fischhoff 2007: 7208). ${ }^{9}$ Only if scientists conduct themselves as neutral and objective communicators of scientific fact, Fischhoff concludes, can they avoid public distrust. Scientists should focus on 'letting the science speak for itself' (Fischhoff 2007: 7204).

Like Plato and Fischhoff, Aristotle recognizes the potential dangers of rhetoric and criticizes sophists who focus on the effectiveness of engaging irrelevant emotions and show no regard for 'facts' (Rhet. 1.1.3-6). ${ }^{10}$ Yet, unlike Plato in the Gorgias, Aristotle does not dismiss rhetoric outright. Instead, he argues that rhetoric must be reformed and better utilized. We follow him in holding that legitimate concerns about rhetoric should not entail abandoning persuasive communication altogether.

In particular, Aristotle argues that rhetoric can serve three useful functions in a political community, particularly in non-ideal circumstances. First, the art is necessary to defend truth and preserve justice against those who use rhetoric for pernicious purposes (Rhet. 1.1.12; McCabe 1994: 142-5). Since enemies of truth and justice will inevitably employ rhetoric to win adherents to their side, learning the art of rhetoric is necessary to refute such appeals (Rhet.1.1.12). Moreover, because Aristotle holds the broader philosophical view that humans are naturally attracted to truth (Lear 1988), he argues that rhetoric, in the long run, (p.236) is likely to be most effective when rooted in truthful claims, even though, in the short run, rhetoricians may be able to exploit their art to purvey falsehoods. Since 'humans have a natural disposition for the true and to a large extent hit on the truth', messages based on facts, arguments, and proofs are, other things being equal, 'more persuasive' (Rhet. 1.1.11-12). ${ }^{11}$

Second, rhetoric is useful because audiences have different levels of understanding and expertise. If philosophers or scientists were to speak only amongst themselves about philosophical or scientific issues, they might not need rhetoric at all (Irwin 1996: 143-4; Reeve 1996: 199-200). But not all listeners share this expertise or have the ability 'to see many things all together or to reason from a distant starting point' (Rhet. 1.2.12). ${ }^{12}$ Rhetoric provides a way to communicate ideas to audiences with different levels of technical understanding, which is especially relevant for CCC. Such rhetoric can appropriately track relevant reasons, even if the audience may not be fully able to comprehend all of the evidence or the underlying strength of those reasons.

For Aristotle, however, the purpose of communication is not merely to share theoretical or scientific knowledge; it also serves our human need to deliberate and decide what to do about practical matters that are contingent and uncertain 
(Rhet. 1.2.12-15; see McCabe 1994: 148-52). This points to a third function of rhetoric: it helps to facilitate deliberation and decision about how to act in particular situations, supplying the means to communicate with fellow citizens and deliberate about what action we should take together as a political community (Rhet. 1.2.11-15). Without rhetoric, we would lack resources to communicate about how we ought to act in the face of competing values, even when scientific conclusions are clear.

While Aristotle defends rhetoric for these reasons, however, he also offers 'the sort of defense that sought to reform its subject' (Garsten 2006: 120). First, he seeks to transform rhetoric into an 'art' (techne) governed by specific standards (Garsten 2006: 130). Replying to Gorgias' critique that rhetoric was merely a form of flattery (Gorgias 462c-6a), Aristotle opens the Rhetoric by asserting that rhetoric is an 'art', specifically the art of observing the 'available means of persuasion' (Rhet. 1.1.1-1.2.1, 1.2.7; see Cooper 1994; McCabe 1994: 139-40; Garsten 2006: 129-31). Among these means of persuasion, Aristotle includes: 1) making logical arguments (logos), 2) demonstrating good character and convincing audiences that one can be trusted (ethos), and 3) engaging (p.237) emotions (pathos) (1.2.3-7). On one hand, then, Aristotle-like many contemporary psychologists-recognizes that appealing to logical argument is not always sufficient to persuade an audience, particularly in cases (such as climate change in our day) where factual uncertainty prevents a logical demonstration, or where an audience of non-experts may lack the technical knowledge needed to understand a particular issue. In such contexts, conveying character and engaging emotions can be legitimate means of building trust and persuading an audience, as long as these appeals are rooted in reasons. On the other hand, appeals to character or emotion that fall 'outside the subject' - that have no connection to rational argument or the matter at hand-risk manipulating, deceiving, or distracting an audience and thus impeding their capacity for judgement (1.1.5). ${ }^{13}$ For Aristotle, rhetoric should aim to facilitate, not supplant, the judgement of audiences. Indeed, rhetoric is the means by which people can be enabled to 'judge' what to do: judgement is 'that for the sake of which rhetoric is used' (2.1.2, as translated by Allen 2004: 141; cf. Rhet. 1.1.10; McCabe 1994: 155; Garsten 2006: 115-41).

That Aristotle makes judgement the aim of rhetoric means that persuasion is not simply a one-sided act on the part of the speaker. Rather, its success depends on the agency of audiences, who act as judges of the persuasive effort (McCabe 1994: 158; Bickford 1996: 48; Allen 2004: 155). This emphasis on the activity of the audience incorporates, but usefully goes beyond, models of communication that focus on audience uptake but still allow the audience to be passive so long as speakers take the audience's need and ability to comprehend into account in framing their speech. Aristotle, by contrast, insists on the active agency of both speaker and auditor in shaping the rhetorical relationship and the outcomes of 
deliberation. In this way, Aristotle's art of rhetoric is dialogical, iterative, and relational, making room for citizen judgement and response. ${ }^{14}$

Aristotle's concern for judgement also points to a second rhetorical reform: he ties rhetoric more closely to deliberation and thereby highlights an important kind of civic equality between speaker and auditor. As Allen observes, Aristotle describes how one 'consents' to speech in the case of horizontal and equal relationships, in contrast to the ways in which speech is used to command in relationships between father and child or master and slave (Allen (p.238) 2004: 142, citing NE 1.13.18 and Rhet. 2.19.9-10). For Aristotle, shared citizenship would exemplify a relationship of equals, among whom persuasion, not force, is the proper mode of interaction.

That civic equality provides the backdrop for persuasion explains why Aristotle seeks to make rhetoric more deliberative. Aristotle argues that the art of rhetoric requires speakers to communicate in ways that preserve audiences' capacity for agency and judgement, treating them as political equals and independent judges rather than passive and pliable recipients. This attention to judgement helps to explain Aristotle's innovative emphasis on deliberative rather than judicial rhetoric (Garsten 2006: 117-29, drawing on Garver 1994; Rorty 1996: ix-x). As scholars have noted, the most prominent form of rhetoric in Aristotle's time was the kind practised in Athenian courts of law, where orators used rhetoric to excite the passions of the people and incite anger toward oligarchs to usurp their power or property (Garsten 2006: 117-24). In the Politics, Aristotle advances a strong critique of this judicial practice (Pol. 1274a5, 1304b21-1305a7, 1305b34, 1310b15, 1320a5, cited by Garsten 2006: $121,237-8 n 13-15)$. Aristotle extends that critique in the Rhetoric, where he criticizes litigants who make emotional appeals that 'do not relate to fact' or 'warp the jury by leading them into anger or envy or pity', thereby driving a wedge between classes (Rhet.1.1.3-5). Aristotle attributes part of the problem to specific features of the judicial setting, features which in our time attach to very different contexts. In the Athenian courts, for example, citizens are asked to make judgements about 'other people's business', which makes them more susceptible to distraction and deception (Rhet. 1.1.10; McCabe 1994: 141; Garsten 2006: 119-24). When jurors' personal interests are not at stake, they are more easily tempted to listen for amusement and allow persuasive speakers to pervert their judgements. In a deliberative assembly, by contrast, a citizen 'judges about matters that affect himself' (Rhet.1.1.10). This personal investment in the outcome of deliberation makes citizens more concerned about their interests, more attentive to the issues under deliberation, and more likely to 'guard against' the rhetorical abuses of demagogues (Rhet. 1.1.10; Garsten 2006: 119-25). For this reason, Aristotle seeks to make deliberative rhetoric, not judicial rhetoric, the paradigm of persuasive communication (Garsten 2006: 125). From this contrast we can learn to be wary of settings in which people see 
themselves as spectators of others' claims rather than as agents invested in the effects of decisions they themselves make.

Aristotle's emphasis on deliberation can offer useful guidance for CCC. In particular, it suggests that communicators should, so far as possible, shift their venues of choice away from the sound-bite culture of mass media, where adversarial, impersonal, and truncated exchanges mirror key aspects of the judicial rhetoric that Aristotle criticizes. In lieu of such potentially distorting and distracting settings, climate communicators should also seek out more (p.239) deliberative forums, such as civic organizations, community groups, municipal governments, or religious communities, which engage audiences' values and interests and allow more time for iterated dialogue and convergence around common aims. If Aristotle is right that people are better judges when their interests are at stake, audiences are likely to make better decisions about how to respond to climate change when they are invited to recognize how it affects their own communities and commitments.

In this way, an Aristotelian approach affirms recent attempts to localize deliberation around climate change and empower local communities to make informed judgements. Many scientists and environmentalists tend to focus exclusively on climate change at the global level and construe the problem in more abstract, technical, and statistical terms (for analysis, see Weber 2006). This emphasis on abstract, distant events can cause many non-expert audiences to view the issue as tangential to their own interests, making them less attentive to relevant facts, less engaged in political deliberation, and more susceptible to irrelevant rhetorical appeals. By connecting climate change to concrete issues, such as the dangers of pollution in local watersheds or the effects of increased temperatures on a region's staple crops, CCC can make communication more deliberative and empower citizens to make better judgements about an issue that affects a range of communities (Schlosberg 2013). This approach fits well with research in psychology and social science. Scholars have shown that people with 'high involvement' and personal investment in an issue are typically motivated to process persuasive communications more carefully and systematically (Chaiken 1980, cited by Dunwoody 2007: 96). Scholars also suggest that some people are more receptive and responsive to climate communications that engage local issues in concrete terms (e.g. Rayner and Malone 1997: 333; Hassol and Udall 2003; Lorenzoni and Pidgeon 2006; Weber 2006; Leiserowitz 2007: 53-4; Moser and Dilling 2007b: 500; Pratt and Rabkin 2007; CRED 2009: 9-10; O'Neill and Nicholson-Cole 2009; Hart and Nisbet 2012: 717). ${ }^{15}$ An Aristotelian art of rhetoric can incorporate-and explain-the importance of localized deliberation.

Yet this Aristotelian insight need not constrict effective CCC only to local contexts. Rather, it suggests ways of connecting local contexts to wider circles of concern in an organic way. A good example is the way a similar approach helped 
to improve deliberative outcomes at the IPCC in the course of the 5th Assessment Report (AR5). Navroz K. Dubash, Marc Fleurbaey, and Sivan (p. 240) Kartha (2014) observe that government representatives were able to reach expanded agreement on one controversial section of the Summary for Policymakers (SPM) of Working Group III when they had four days to discuss the text and understand the distinctive challenges that diverse countries faced. By contrast, discussions of later sections of the SPM were subject to stricter time limits, which fostered conflict, disagreement, and distrust, forcing representatives to settle for a truncated and simplified agreement. Given this contrast, Dubash, Fleurbaey, and Kartha recommend 'creating more channels and space for dialogue before the pressure cooker of a time-limited approval session, ensuring strict continuity and transparency between drafts, and treating author diversity of perspectives as an asset' (Dubash, Fleurbaey, and Kartha 2014: 37). These recommendations align with the Aristotelian approach we recommend.

That Aristotle focuses on citizens' judgements about their own interests, however, does not mean that he encourages egoism or self-interest. It is a commonplace, but an important one, that 'ethics' in Aristotle's sense aims at an individual flourishing (eudaimonia) that is understood as substantively interconnected with being part of a well-ordered political community. Because Aristotle believed that all human beings are 'political animals', he expected that citizens' conceptions of the good will, in well-functioning polities, be directly tied to the good of their political communities (NE 1.2.4-8, 9.9.3; Garsten 2006: 1267). Thus, when citizens deliberate well about what to do, they will be deciding what is best for the entire political community, not just for themselves or their households.

This inclusive notion of deliberation points to a third way in which Aristotle seeks to reform rhetoric: he subordinates rhetoric to ethics and politics. ${ }^{16}$ Ethics enters into rhetoric in two ways. The first is more familiar: ethics attaches to the outcome of deliberation or the opinion to be formed through deliberation. Some outcomes and opinions are more conducive to the common good than others. Second, and most relevant for our purposes, ethics enters rhetoric because the relationship between speaker and listener is itself an ethical forum in which the listener needs to decide whether the speaker is trustworthy, and the speaker has to demonstrate herself to be such. By taking the relationship itself to be at stake, Aristotle reveals an ethical substratum to any act of persuasion, including the forms that social psychology studies today. Since there is no communication without a frame of relationship, communication cannot be construed outside the ethics associated with that (p.241) frame. The ethics of relational communication must be part of any act of democratically relevant rhetoric, whatever more specific ethical framework a speaker may seek to advance. 
If Aristotelian ethics is not in the first instance a set of limits and constraints, but a perspective on how humans can flourish in their relationships with others in the long run, it may seem ill suited to addressing the CCC problems we have identified: if Aristotle cannot help us draw a simple ethical line between manipulative (unacceptable) rhetoric and acceptable rhetoric, or between ethical and unethical approaches to gaining trust, what use is he in solving the problems we have identified in contemporary psychologists' studies of CCC? In fact, the broader Aristotelian perspective may be able to help us where narrower attempts to tie manipulation to our 'pre-existing will' cannot. Rather than looking for a simple line to guide elite strategic deployment of one-off cases of manipulative communication, Aristotle directs our attention to a set of long-term interests that include the ability of audiences to judge for themselves whether that line has been crossed. Here we see the moral force of casting auditors as 'judges', a force that even the modern work in the ethics of communication has not fully explored. For Aristotle, the questions of manipulation, and of trust in communication more broadly, are questions for audiences to judge, not for elites to predetermine for them. An Aristotelian perspective thus suggests that the ethics committees in psychology may have been partly looking in the wrong place. The issue is not whether psychologists are drawing exactly the right ethical lines in framing, but whether they recognize that the ultimate judges of their ethical choices of line-drawing and framing will be the auditors themselves. Moreover, since auditors will make their judgements over time, in the context of past communicative acts and ongoing relationships with speakers, an Aristotelian approach recognizes that building trust and admitting uncertainty are key features of the communicative relationship. Psychological studies that examine this relationship tend to portray it as a static given or as utterly malleable to strategic reframing. Aristotle, by contrast, casts the communicative relationship as a dynamic and diachronic context to which ethics appropriately attaches. In these ways, Aristotle furnishes an account of ethical communication that can complement current research in CCC.

\subsection{Rhetoric as the Art of Trust Production: A CCC Challenge and an Aristotelian Response \\ We turn now to a particular practical challenge that CCC research has identified and to which we believe Aristotle can help fashion a response. The challenge involves the ways in which cognitive competence, on the one (p.242) hand, and perceived trustworthiness, on the other, can come apart in audiences' judgements about particular climate change communicators in non-ideal circumstances.}

In a recent study, psychologists Susan Fiske and Cydney Dupree identify two key dimensions of communicator credibility: perceived expertise and trustworthiness (Fiske and Dupree 2014). In many cases, the perception of expertise is a default cue for listener trust, encouraging listeners to defer to an expert as trustworthy. But if a perception of conflict between experts prompts a listener to scrutinize 
an expert's communication rather than defer to default cues, Fiske and Dupree demonstrate that listeners will often scrutinize not only the speaker's knowledge but also her intentions, assessing whether she is well disposed to the listener's goals, interests, and values. If the speaker's motives are not clearly evident or expressed, their studies suggest that listeners will rush in to attribute trustworthiness (or the lack thereof) based on perceptions of a speaker's intentions, competence, and character (Fiske and Dupree 2014: 13593-4).

Fiske and Dupree apply this research to CCC in particular by showing how perceptions of trustworthiness-in which perceptions of intent ('warmth') can be at odds with perceptions of capability ('competence')-affect the credibility of communicators from diverse occupational groups. With significant cross-cultural continuity, their experiments highlight a problem of 'cold competence', where groups viewed as competent but cold are not trusted to share the goals and values of listeners. Whereas 'teachers' and 'professors' are typically viewed as warm and well intentioned, for example, 'scientists' and 'researchers' are often perceived as competent but lacking good intentions. As a result, Fiske and Dupree argue, scientists are regarded with potential 'envy', an attitude that generates distrust and causes 'cold competent' people to lack communicative credibility (Fiske and Dupree 2014: 13595-6). Since so many of those who engage in CCC are perceived (or framed) as 'scientists' or 'researchers', this problem of 'cold competence' poses special challenges for CCC.

How might Aristotle help to fashion a response to the problem of 'cold competence'? As noted above, Danielle Allen has described Aristotelian rhetoric as an 'art of trust production' by which a speaker overcomes 'challenges of distrust' by utilizing distinctive communicative capacities '(1) to make logical arguments [logos], (2) to convey character [ethos], and (3) to engage the emotions of our audience [pathos]' (Allen 2004: 141, 143-4). ${ }^{17}$ Aristotle suggests (p.243) that speakers who develop these capacities can cultivate trust and alleviate the distrust that emerges from factual or interpersonal sources (Allen 2004: 143-4). Moreover, since each of these capacities interacts with the others, his account also highlights how these capacities should be considered in dynamic interplay rather than as a static matrix of distinct dimensions. In this way, Aristotle's model improves on both the one-dimension cognitivist picture of communication dominant in much modern philosophy and the two-dimension picture of competence-plus-warmth considered independently in much modern psychology.

Most work on the ethics of CCC focuses on effectively communicating the conclusions of climate science while respecting and conveying limits imposed by uncertainty (see Keohane, Lane, and Oppenheimer 2014). Aristotle has interesting insights to add as to how to convey logos or argument. The basic structure of rhetorical argument that he identifies-the enthymeme or rhetorical syllogism-involves appeal to 'premises held by the audience-because 
persuasion cannot take place unless the audience views a conclusion as required by the premises it subscribes to' (Bitzer 1959: 405). On this view, the effective speaker should make logical appeals that have some relation to audiences' existing views (endoxa), though she may aim to persuade audiences to recognize previously unacknowledged implications of their views, or to discard some previous commitments as incompatible with other beliefs or with new information. In these cases, the speaker may plausibly seek to change the audience's pre-existing will to act, but even then, she must appeal to common starting points that are at least familiar to the audience (see Rhet. 1.1.11, 1.2.13; Irwin 1996).

Even when speakers begin with the existing views of their audience, however, Aristotle recognizes that epistemic uncertainty and expert disagreement will sometimes inhibit lay audiences from consenting to an argument based solely on logic. Here Aristotle offers additional resources for addressing distrust. As Allen argues, Aristotle's appeal to the character of communicators offers one way to 'dispel the distrust arising from factual uncertainty' (2004: 145-6). When lay citizens confront uncertainty about the future, as they frequently do in climate change deliberations, the character of speakers can inform decisions about whom to trust. Consider an example from Christopher Kutz, a legal philosopher who confronted epistemic uncertainty and expert disagreement in another scientific domain, medicine (Kutz n.d.). Suffering from a physical ailment, Kutz consulted several highly respected, highly credentialled physicians, who offered conflicting diagnoses and recommendations for treatment. Without comparable medical expertise, Kutz could not rely on factual knowledge to decide whom to trust, so he decided to trust the expert who displayed the most personal virtues as a clinician and communicator, the one who 'took time' with him, 'listened patiently' to his (p.244) observations, showed 'attentiveness' to his individual symptoms, and 'explained the options clearly'. Kutz, in short, relied on the character of the doctor as a sign of expertise (not vice versa), and in this particular case, it led to the right decision: surgery revealed that the trusted doctor's diagnosis was correct (Kutz n.d.; cf. Manson and O'Neill 2007: 32). Reflecting on this and related experiences, Kutz draws what we consider an Aristotelian conclusion: in many cases of epistemic uncertainty, an expert's character can be a useful guide for knowing whom to trust.

While Aristotle has much to say about logos and its interactions with ethos, he perhaps adds the greatest value to CCC in addressing the interaction of ethos and pathos in producing trust. Combining ethos and pathos (and certain cognitive dimensions, too), the problem of 'cold competence' highlighted above is one where the character and intentions of the speaker are scrutinized and deemed suspicious by the audience. In Aristotle's terms, as for Fiske and Dupree, if audiences become motivated to challenge speakers, then the expertise in logos that normally generates a default attitude of trust will no longer be sufficient. Once a challenge is raised or created-for example, by 
those who artificially posit a 'debate' where there is none-suspicion needs to be addressed lest it corrode into distrust. Aristotle offers useful insights to address the suspicion that 'cold but competent' speakers lack goodwill toward their audiences.

For Aristotle, ethos, or character, integrates cognitive, moral, and affective dimensions, and each can constitute a specific kind of failure. First, we can experience a failure of trust along cognitive dimensions when an auditor thinks a speaker lacks knowledge or wisdom, believing that the speaker does not know what he claims to know, or is not to be trusted in judging what should be done or thought. Aristotle calls this a failure of 'good sense' (phronesis) (Rhet. 2.1.5-7). It involves a partly cognitive failure, not necessarily of (what we would call) scientific competence, but rather of the ability to translate that competence into (what we might call) practical policy decisions. This failure is perceived as a character flaw insofar as it generates suspicions about the speaker's claim to know something relevant to what should be done.

Second, an auditor may credit the speaker with good sense, but still distrust him if she thinks he lacks virtue (arete): one does not typically trust the good sense of someone who may, for example, be immoderate, unjust, or cowardly (Rhet. 2.1.5-7; cf. McCabe 1994: 161-2). In the case of climate change, a person who is knowledgeable may lack the courage to defend his convictions in the face of challenge or the humility to listen to those with different forms of expertise. Such failures of character can generate distrust.

Finally, and perhaps most relevant to the social psychology of CCC, an auditor may credit a speaker with good sense and virtue, but still find that he lacks the emotional attitude of 'goodwill' (eunoia) toward herself or her group, (p.245) which causes her to withhold trust or even question his good sense and virtue (Rhet. 2.1.5-7). This case may be hard for modern readers to understand: how could someone be simultaneously judged to be broadly virtuous and yet ill disposed toward a particular auditor or her group? In fact, this is one of the most interesting ways in which Aristotle's account of rhetoric modifies his ethics. Someone may have the moral virtues and be disposed to act rightly in relation to choices he faces himself and even to treat others fairly in general, but it does not follow that he will be-or will be perceived to be-well disposed to every particular audience so as to advise them well about particular cases. This is precisely the kind of case that Fiske and Dupree highlight: one in which scientists and researchers (among others) are judged by particular auditors as failing to exhibit warmth or goodwill toward them and the groups to which they belong.

To address such distrust, Aristotle spends the bulk of Book 2 analysing the emotions, focusing particularly on those related to perceptions of the speaker's goodwill and 'friendliness' (philia) (Rhet. 2.1.7; Bickford 1996: 35-53). Here 
pathos becomes a further dimension in the evaluation of ethos. Aristotle investigates a long list of negative emotions that may lead auditors to be ill disposed to a speaker and to believe that the speaker is ill disposed toward them. In fact, Aristotle analyses eight negative emotions-'anger, fear, shame, charity, pity, indignation, envy, emulation' - that need to be converted into 'mildness' or 'confidence', the absence of pain or fear (Allen 2004: 150).

Most of these negative emotions reflect a sense of loss or pain, which makes an auditor feel that a speaker's interests may be opposed to her own (Allen 2004: 149-50). Again, this insight matches the research in social psychology, where distrust issues from the suspicion that speakers may be pursuing interests opposed to, or divergent from, the values and interests of the auditor and her group. Fiske and Dupree find that climate scientists in particular are distrusted on grounds of intent, often being imputed to have 'alleged motives to lie with statistics, complicate a simple story, show superiority, gain research money, pursue a liberal agenda, provoke the public, and hurt big corporations', with money being the far most salient among these (Fiske and Dupree 2014: 13596). Fiske and Dupree suggest that, once the public has been motivated to scrutinize the communication of climate scientists (however unfair or arbitrary those promptings may have been), scientists do not have the luxury of neglecting intent. If scientists do not succeed in showing themselves to have trustworthy motives, bad intent will be attributed to them.

Fiske and Dupree (2014) themselves propose that this distrust could be mitigated in part by scientists 'whose job involves teaching and communicating', activities viewed by their experimental subjects as trustworthy in their intentions rather than associated with coldness and envy. This is concomitant with a widespread approach among social psychologists studying CCC, who (p. 246) are inclined to propose new forms of framing that may be more effective than existing ones. Aristotle's insights, however, should make us cautious about this approach if applied uncritically. According to an Aristotelian perspective, no simple act of reframing is likely to be enough-if only because reverse reframing will be all too easy, and reframing as such is always vulnerable to being perceived or painted as manipulation. It is this risk that many empirical studies of CCC have perhaps been too blasé about. Without the context of long-term trust that an ethical rhetoric is committed to fashioning, the reframings recommended by such studies might easily be perceived as pandering or manipulation, even 'rhetoric' in the pejorative sense. The problem of intent or goodwill, and of the associated emotions that accompany it, needs to be addressed openly if speakers are to demonstrate goodwill and earn the trust of auditors. Indeed, an Aristotelian approach recognizes that drawing a line between ethical and unethical acts of communication is not a technocratic issue that climate communicators can simply determine on their own, but ultimately remains in the hands of the audience to judge. While communication inherently aims to change audiences' views in some respect, it will not succeed unless it is 
sensitive to audiences' starting points and acknowledges their ultimate authority in determining how and whether to revise their views.

To guide the process of ethical communication, Aristotle explores how each kind of negative emotion may be avoided, quieted, or harnessed to promote better judgement. While full consideration of his analysis is beyond the scope of this chapter, dividing the most relevant emotions into two categories brings out affinities with the findings of Fiske and Dupree and, with them, valuable potential responses.

The first category includes emotions that evince superiority, which, when perceived as such, can give auditors the impression that speakers' interests are different from their own. Anger is one of these emotions. According to Aristotle, we often feel anger toward speakers who show 'hubris' or 'contempt', those who 'speak badly of, and scorn, things that [we] take most seriously', and who 'do not care if [we] are suffering' (Rhet. 2.2.12-27). This last source of indifference, Aristotle argues, is why we 'become angry at those announcing bad news' (Rhet. 2.2.20). Here, we can see a relevant parallel to CCC, which is sometimes perceived as 'talking down' to lay audiences, showing 'contempt' for traditional worldviews, or remaining indifferent to the cultural and social loss that may come from drastic change. One scientist turned actor and filmmaker suggests that one way in which climate communicators may demonstrate inadvertent but perceived hubris is by sticking relentlessly to their talking points and thus seeming unresponsive to the specific questions asked by their interviewers. He suggests an alternative strategy based on improvisation (in improvisation parlance, using the technique of saying 'yes and' (p.247) instead of 'no but'), which can demonstrate a form of equality in which one accepts an element of the other's starting point as one's own (Olson 2009).

Envy (phthonos) is another emotion related to perceptions of superiority. As opposed to 'pity' and 'indignation', where the judgement is in a sense a morally disinterested one, Aristotle stresses that envy is excited by the success not 'of someone who is unworthy' but 'of an equal and a like', someone, he implies, who is superior in enjoying some attribute or possession that one feels should or could be one's own (Rhet. 2.9.3). ${ }^{18}$ Insofar as envy undermines trust in a speaker's goodwill, the envied speaker is believed to lack goodwill toward the envious audience, which can in turn generate distrust.

The relationship between envy and the absence of goodwill points to a second relevant category: emotions of good (or bad) will toward those whom we presume have good (or bad) intent toward us. Envy belongs in this category, too, along with emotions relating to 'friendliness' and 'enmity'. Aristotle describes 'friendliness' as 'wanting for someone what one thinks are good things for him, not what one thinks benefits oneself' (Rhet. 2.4.1), which is akin to what Fiske and Dupree (2014) describe as beneficent intent or goodwill. Like Fiske and 
Dupree, Aristotle notes that we tend to be friendly toward 'those who are like ourselves in character and occupation' and 'who are honest with us' (Rhet. 2.4.21, 2.4.27, translation from Roberts 1984). Toward the deceitful or disagreeable we may feel not 'friendliness' but 'enmity,' which increases one's sense of distance and distrust (Rhet. 2.4.30).

Like enmity and anger, fear (phobos) also generates suspicion toward speakers whose motives seem harmful to us. While Aristotle describes fear as 'a sort of pain and agitation derived from the imagination of a future destructive or painful evil', he recognizes that not all evils generate fear, especially those perceived as distant or remote, since 'what is far off is not feared' (Rhet. 2.5.1). This account may help to explain the mixed reactions that many audiences have to climate change communicators. On the one hand, if audiences believe the effects of climate change are 'far off', they may feel no need to listen to speakers communicating about events perceived to be distant. Psychological research affirms that people give less weight to climate change when it is perceived as an abstract or remote risk (Weber 2006: 110). On the other hand, if climate change communicators stress that events are near at hand, they can generate fear in the audience and suspicion towards speakers, leading to resentment, anger, and distrust toward these bearers of bad news. This may help to explain why 'fear appeals' in CCC are often ineffective at generating action when not paired with more positive guidance about how to (p.248) respond effectively to the threat (see Moser 2007; O’Neill and Nicholson-Cole 2009; McQueen 2014).

How can, and how should, a climate change communicator neutralize these negative emotions and harness positive emotions to encourage more responsive acts of communication and judgement? ${ }^{19}$ On an Aristotelian account, the primary aim of communicators who take on this role in a division of labour amongst scientists should be to transform strong negative emotions into 'mildness' and then, in a further step, 'to convert mildness to goodwill' (Allen 2004: 152). In part, this can be achieved by 'those who humble themselves', since humility tends to neutralize negative emotions such as anger and envy, which follow from perceptions of a speaker's superiority (Rhet. 2.3.6-8) ${ }^{20}$ By avoiding 'patronizing their fellow citizens', by being 'willing to share power with their audiences and to make themselves vulnerable to them', and by considering whether proposals are acceptable from other points of view, speakers can show respect for their audiences' equality and judgement, thereby expressing a form of goodwill over time, not merely the transient and unstable goodwill generated by strategic reframings (Allen 2004: 152-3). Real goodwill is earned not by seeking an audience's acquiescence in predetermined proposals but by demonstrating a record of care and concern for an audience's agency, interests, and judgements over time, which shows that a speaker's relation to her own interests can be trusted (152-4). 
This Aristotelian art of rhetoric can help climate change communicators avoid the manipulation often associated with 'rhetoric' in the popular sense. This approach suggests, for example, that the sinister motives with which climate change scientists are readily credited (or burdened) can be countered by making more beneficent motives visible. While Aristotle might affirm Fiske and Dupree's suggestion that speakers communicate their intent to teach, he would insist that presenting oneself as a teacher entails an important implication: one must actually be willing to teach, demonstrating in practice that one actually has the beneficent intent being professed. Otherwise, framing oneself as a teacher could generate distrust. By situating communication with an ongoing and long-term communicative relationship, Aristotle's focus on trust thus goes beyond tactical reframing and generates a range of other ethical and political commitments: maintaining transparency about how a course of action affects one's own interests, showing equity in addressing one's own interests in relation to others, and sometimes even sacrificing one's interests to promote those of the audience, all of which, Allen argues, serve 'to prove that one's approach to self-interest is trustworthy' (Allen 2004: 154). Indeed, (p.249) Aristotle recognizes that sacrificing some aspect of one's own advantage for the sake of auditors is an especially effective way to express humility, model equity, and build trust (Allen 2004: 154, citing NE 5.10.8). By demonstrating that one is willing to share power and accept decisions that benefit oneself less than others, verbal and practical expressions of humility, equity, and sacrifice show that a speaker is not bypassing deliberation or manipulating an audience, but rather is committed to 'judging with' (suggnome) the audience, expressing their willingness to moderate or subordinate their interests to the common good (Allen 2004: 154).

This is an important message for CCC. Once debate or challenge has motivated an audience to question a climate scientist's ethos and pathos, trust can no longer be taken for granted, and speaking purely in terms of rational or scientific argument (logos) may well exacerbate distrust. Only by demonstrating how and why they are trustworthy can even scientifically competent speakers earn credibility. Aristotle's art of rhetoric highlights how scientists can earn this trust by displaying equity and humility, emphasizing respect for the agency and judgement of citizens, and acting in ways consistent with that respect, such as listening carefully to their concerns, showing a willingness to share power over the outcome of deliberation, and avoiding technical jargon or expressions of superiority that might generate anger, envy, or enmity. Indeed, the same activities that elicited Kutz's trust in scientific experts-listening patiently, engaging in conversation, showing attentiveness to an audience's values and circumstances, and explaining options clearly—can help climate change communicators earn trust, too. Such activities may require sacrifices of time, money, power, and prestige, along with other traditional academic markers of 'success', but if sacrifice is one of the most important ways to demonstrate equity, goodwill, and trustworthiness, these sacrifices may help convince 
audiences that speakers are communicating messages for the audiences' benefit, not just for their own. ${ }^{21}$

In addition to countering suspicions of scientists' motives, an Aristotelian approach may also help communicators rise above the polarization surrounding the climate change debate. ${ }^{22}$ Like ancient sophists, many climate change denialists have no qualms about using pernicious appeals 'outside the subject' to manufacture disagreement, challenge the scientific consensus, and paint climate scientists as motivated solely by money, power, or ideology (see (p.250) McCright 2007; Oreskes and Conway 2010). Given the intensity and impact of this denialism, many climate scientists and advocates may be tempted to combat it by using new tools from psychology. The danger is that, without any consideration of the ethical impacts of these tools, the public may come to see such attempts as deception, pandering, or manipulation, which might only harden resistance. An Aristotelian approach focused on building trust and demonstrating character and goodwill-especially when applied at both the institutional and individual level by scientists, policymakers, and communicators - could be an antidote to such polarization, enabling more trustworthy voices to rise above the fray. More empirical work is needed to assess this possibility, but if Aristotle is right that truthful messages are 'more persuasive' in the long run (Rhet.1.1.11-12), an Aristotelian art of trust production not only treats audiences with the equity and respect they deserve but may also prove a more effective way to motivate sustainable responses to climate change. When audiences are starved of trustworthy voices, an Aristotelian approach to ethical CCC may ultimately be more effective.

\subsection{Conclusion}

Compared with existing models of CCC, an Aristotelian form of persuasive communication puts less emphasis on strategic reframing and more on the ethical and political relationship between speaker and audience. By developing this relationship along dimensions of logos, ethos, and pathos, Aristotle's art of rhetoric helps to foster relationships in which speakers and auditors are civic equals, auditors' agency and judgement are respected, and possible grounds for distrust are alleviated. Such relationships can facilitate ongoing acts of successful communication, even when factual uncertainty and expert disagreement threaten to incite division. Ultimately, by alerting climate change communicators to the importance of these ethical and political relationships, an Aristotelian approach highlights how rhetoric can be an art of earning trust. Contemporary climate change communicators can learn much from Aristotle's ancient advice.

\section{Acknowledgements}

We are grateful to the Princeton Institute for International and Regional Studies for supporting this research under the auspices of its research community on 
'Communicating Uncertainty: Science, Institutions, and Ethics in the Politics of Global Climate Change', and for support of this research by the Templeton World Charity Foundation. We are also indebted to friends and colleagues who offered helpful feedback on (p.251) previous drafts of the chapter, especially the editors of this volume along with Chiara Cordelli, Andrew Fitzmaurice, Marc Fleurbaey, Bryan Garsten, Philip Hannam, Niki Harré, Johannes Himmelreich, Duncan Ivison, Desmond Jagmohan, Susan James, Steven Kelts, Geoff Kemp, Robert Keohane, Martin Korwarsch, Minh Ly, Hallie Liberto, Isabella Litke, Dan Lunney, Ezra Markowitz, Victoria McGeer, Andrew McGonigal, Janet McLean, Alison McQueen, John Morrow, Tim Mulgan, Michael Oppenheimer, Alan Patten, Philip Pettit, David Schlosberg, Mary Sewell, Peter Singer, Angela Smith, Kathy Smits, Lucas Stanczyk, Amy Dru Stanley, Anna Stilz, Alec Walen, Martin Wilkinson, Stephen Winter, and audiences at the University of Auckland (for the 2015 Hood Lecture), Sydney Environment Institute, Roger Mudd Center for Ethics at Washington and Lee University, University of North Carolina-Asheville, University of Cambridge Graduate Conference in Ancient Philosophy, Princeton Workshop on Epistemic Democracy, Laurence S. Rockefeller Seminar at the Princeton University Center for Human Values, and Oxford Martin School.

\section{References}

\section{Bibliography references:}

Agyeman, Julian, Bob Doppelt, Kathy Lynn, and Halida Hatic. 2007. 'The Climate-Justice Link: Communicating Risk with Low-Income and Minority Audiences'. In Creating a Climate for Change: Communicating Climate Change and Facilitating Social Change, ed. Susanne C. Moser and Lisa Dilling, pp. 11938. New York: Cambridge University Press.

Allen, Danielle S. 2004. Talking to Strangers: Anxieties of Citizenship after Brown v. Board of Education. Chicago: University of Chicago Press.

Aristotle. 1984. Rhetoric, trans. W. Rhys. Roberts, in Jonathan Barnes, ed. The Works of Aristotle, vol. 2, pp. 2152-269. Princeton, NJ: Princeton University Press.

Aristotle. 1997. Politics, trans. C. D. C. Reeve. Indianapolis, IN: Hackett.

Aristotle. 1999. Nicomachean Ethics, trans. Terence H. Irwin, 2nd ed. Indianapolis, IN: Hackett.

Aristotle. 2006. On Rhetoric: A Theory of Civic Discourse, trans. George A. Kennedy, 2nd ed. New York: Oxford University Press.

Barnes, Jonathan. 1995. 'Rhetoric and Poetics'. In The Cambridge Companion to Aristotle, ed. Jonathan Barnes, pp. 259-85. Cambridge: Cambridge University Press. 
Bickford, Susan. 1996. The Dissonance of Democracy, Listening, Conflict, and Citizenship. Ithaca, NY: Cornell University Press.

Bitzer, Lloyd F. 1959. 'Aristotle's Enthymeme Revisited'. Quarterly Journal of Speech 45: pp. 399-408.

CRED (Center for Research on Environmental Decisions) 2009. The Psychology of Climate Change Communication: A Guide for Scientists, Journalists, Educators, Political Aides, and the Interested Public. New York: CRED.

Chaiken, Shelly. 1980. 'Heuristic Versus Systematic Information Processing and the Use of Source Versus Message Cues in Persuasion'. Journal of Personality and Social Psychology 39: pp. 752-66.

(p.252) Chess, Caron and Branden B. Johnson. 2007. 'Information Is Not Enough'. In Creating a Climate for Change: Communicating Climate Change and Facilitating Social Change, ed. Susanne C. Moser and Lisa Dilling, pp. 223-33. New York: Cambridge University Press.

Cooper, John M. 1994. 'Ethical-Political Theory in Aristotle's Rhetoric'. In Aristotle's Rhetoric: Philosophical Essays, ed. David J. Furley and Alexander Nehemas, pp. 193-210. Princeton, NJ: Princeton University Press.

Dubash, Navroz K., Marc Fleurbaey, and Sivan Kartha. 2014. 'Political Implications of Data Presentation'. Science 345 (6192): pp. 36-7.

Dunwoody, Sharon. 2007. 'The Challenge of Trying to Make a Difference Using Media Messages'. In Creating a Climate for Change: Communicating Climate Change and Facilitating Social Change, ed. Susanne C. Moser and Lisa Dilling, pp. 89-104. New York: Cambridge University Press.

Fischhoff, Baruch. 2007. 'Non-Persuasive Communication about Matters of Greatest Urgency: Climate Change'. Environmental Science \& Technology 41: pp. 7204-8.

Fiske, Susan T. and Cydney Dupree. 2014. 'Gaining Trust as Well as Respect in Communicating to Motivated Audiences about Science Topics'. Proceedings of the National Academy of Sciences. Vol. III, Supplement 4: pp. 13593-7.

Furley, David J. and Alexander Nehemas, eds. 1994. Aristotle's Rhetoric: Philosophical Essays. Princeton, NJ: Princeton University Press.

Garsten, Bryan. 2006. Saving Persuasion: A Defense of Rhetoric and Judgment. Cambridge, MA: Harvard University Press.

Garver, Eugene. 1994. Aristotle's Rhetoric: An Art of Character. Chicago: University of Chicago Press. 
Goodin, Robert E. 1980. Manipulatory Politics. New Haven, CT: Yale University Press.

Harré, Niki. 2012. Psychology for a Better World: Strategies to Inspire Sustainability. Auckland: Department of Psychology, University of Auckland.

Hart, P. Sol and Erik. C. Nisbet. 2012. 'Boomerang Effects in Science Communication: How Motivated Reasoning and Identity Cues Amplify Opinion Polarization About Climate Mitigation Policies'. Communication Research 39: pp. 701-23.

Hassol, Susan Joy and Randy Udall. 2003. 'A Change of Climate'. Issues in Science and Technology 19 (3): pp. 39-46.

Irwin, Terence H. 1996. 'Ethics in the Rhetoric and in the Ethics'. In Essays on Aristotle's Rhetoric, ed. Amélie Oksenberg, pp. 142-74. Berkeley: University of California Press.

Jamieson, Kathleen Hall and Bruce W. Hardy. 2014. 'Leveraging Scientific Credibility about Arctic Sea Ice Trends in a Polarized Political Environment'. Proceedings of the National Academy of Sciences 111, suppl. 4: pp. 13598-605.

Judd, Charles M., Laurie James-Hawkins, Vincent Yzerbyt, and Yoshihisa Kashima. 2005. 'Fundamental Dimensions of Social Judgment: Understanding the Relations between Judgments of Competence and Warmth'. Journal of Personality and Social Psychology 89: pp. 899-913.

Kahan, Dan. 2010. 'Fixing the Communications Failure'. Nature 463 (7279): pp. 296-7.

Keohane, Robert O., Melissa Lane, and Michael Oppenheimer. 2014. 'The Ethics of Scientific Communication under Uncertainty'. Politics, Philosophy and Economics 13: pp. 343-68.

(p.253) Kutz, Christopher. n.d. 'Epistemethics: Virtue and Judgment in Medicine, Law, and Politics'. Unpublished manuscript.

Lane, Melissa. 2011. Eco-Republic: Ancient Thinking for a Green Age. Oxford: Peter Lang.

Lane, Melissa. 2014. 'When the Experts are Uncertain: Scientific Knowledge and the Ethics of Democratic Judgment'. Episteme 11: pp. 97-118.

Lear, Jonathan. 1988. Aristotle: The Desire to Understand. Cambridge: Cambridge University Press. 
Leiserowitz, Anthony. 2006. 'Climate Change Risk Perception and Policy Preferences: The Role of Affect, Imagery, and Values'. Climatic Change 77: pp. 45-72.

Leiserowitz, Anthony. 2007. 'Communicating the Risks of Global Warming: American Risk Perceptions, Affective Images, and Interpretative Communities'. In Creating a Climate for Change: Communicating Climate Change and Facilitating Social Change, ed. Susanne C. Moser and Lisa Dilling, pp. 44-63. New York: Cambridge University Press.

Lorenzoni, Irene and Nick F. Pidgeon. 2006. 'Public Views on Climate Change: European and USA Perspectives'. Climatic Change 77: pp. 73-95.

Lupia, Arthur. 2013. 'Communicating Science in Politicized Environments'. Proceedings of the National Academy of Sciences 110, suppl. 3: 14048-54.

McCabe, Mary Margaret. 1994. 'Arguments in Context: Aristotle's Defense of Rhetoric'. In Aristotle's Rhetoric: Philosophical Essays, ed. David J. Furley and Alexander Nehemas, pp. 129-65. Princeton, NJ: Princeton University Press.

McCright, Aaron M. 2007. 'Dealing with Climate Change Contrarians'. In Creating a Climate for Change: Communicating Climate Change and Facilitating Social Change, ed. Susanne C. Moser and Lisa Dilling, pp. 200-12. New York: Cambridge University Press.

McQueen, Alison. 2014. 'Salutary Fear? Hans Morgenthau and Nuclear Catastrophe'. Presentation at the Annual Meeting of the American Political Science Association.

Malka, Ariel, Jon Krosnick, and Gary Langer. 2009. 'The Association of Knowledge with Concern about Global Warming: Trusted Information Sources Shape Public Thinking'. Risk Analysis 29 (5): pp. 633-47.

Manson, Neil and Onora O'Neill. 2007. Rethinking Informed Consent in Bioethics. New York: Cambridge University Press.

Markowitz, Ezra M. and Shariff, Azim F. 2012. 'Climate Change and Moral Judgment'. Nature Climate Change 2: pp. 243-7.

Moser, Susanne C. 2007. 'More Bad News: the Risk of Neglecting Emotional Responses to Climate Change Information'. In Creating a Climate for Change: Communicating Climate Change and Facilitating Social Change, ed. Susanne C. Moser and Lisa Dilling, pp. 64-80. New York: Cambridge University Press.

Moser, Susanne C. 2010. 'Communicating Climate Change: History, Challenges, Process, and Future Directions'. Wiley Interdisciplinary Reviews: Climate Change 1: pp. 31-52. 
Moser, Susanne C. and Lisa Dilling, eds. 2007a. Creating a Climate for Change: Communicating Climate Change and Facilitating Social Change. New York: Cambridge University Press.

Moser, Susanne C. and Lisa Dilling. 2007b. 'Toward the Social Tipping Point: Creating a Climate for Change'. In Creating a Climate for Change:

Communicating Climate Change (p.254) and Facilitating Social Change, ed. Susanne C. Moser and Lisa Dilling, pp. 491-516. New York: Cambridge University Press.

O’Neill, Safron and Sophie Nicholson-Cole. 2009. “"Fear Won’t Do”: Promoting Positive Engagement with Climate Change Through Visual and Iconic Representations'. Science Communication 30, no. 3: pp. 355-79.

Olson, Randy. 2009. Don't Be Such a Scientist: Talking Substance in an Age of Style. Washington, DC: Island Press.

Oreskes, Naomi and Erik M. Conway. 2010. Merchants of Doubt: How a Handful of Scientists Obscured the Truth on Issues from Tobacco Smoke to Global Warming. New York: Bloomsbury Press.

Plato. 1997. Gorgias, trans. Donald J. Zeyl, in Complete Works, ed. John M. Cooper. Indianapolis, IN: Hackett.

Pratt, Linda Giannelli and Sarah Rabkin. 2007. 'Listening to the Audience: San Diego Hones its Communication Strategy by Soliciting Residents' Views'. In Creating a Climate for Change: Communicating Climate Change and Facilitating Social Change, ed. Susanne C. Moser and Lisa Dilling, pp. 105-18. New York: Cambridge University Press.

Rayner, Steve and Elizabeth L. Malone. 1997. 'Zen and the Art of Climate Maintenance'. Nature 390: pp. 332-4.

Reeve, C. D. C. 1996. 'Philosophy, Politics, and Rhetoric in Aristotle'. In Essays on Aristotle's Rhetoric, ed. Amélie Oksenberg Rorty, pp. 191-205. Berkeley: University of California Press.

Regan, Kathleen. 2007. 'A Role for Dialogue in Communication about Climate Change'. In Creating a Climate for Change: Communicating Climate Change and Facilitating Social Change, ed. Susanne C. Moser and Lisa Dilling, pp. 213-22. New York: Cambridge University Press.

Rorty, Amélie Oksenberg, ed. 1996. Essays on Aristotle’s Rhetoric. Berkeley: University of California Press.

Schlosberg, David. 2013. 'Political Challenges of the Climate-Changed Society'. Political Science and Politics 46: pp. 13-17. 
Sprute, Jürgen. 1994. 'Aristotle and the Legitimacy of Rhetoric'. In Aristotle's Rhetoric: Philosophical Essays, ed. David J. Furley and Alexander Nehemas, pp. 117-28. Princeton, NJ: Princeton University Press.

Swim, Janet, Susan Clayton, Thomas Doherty, Robert Gifford, George Howard, Joseph Reser, Paul Stern, and Elke Weber. 2009. 'Psychology and Global Climate Change: Addressing a Multi-faceted Phenomenon and Set of Challenges. A Report by the American Psychological Association's Task Force on the Interface between Psychology and Global Climate Change'. <http://www.apa.org/science/ about/publications/climate-change.pdf $>$ (accessed 27 February 2015).

Weber, Elke U. 2006. 'Experience-Based and Description-Based Perceptions of Long-Term Risk: Why Global Warming Does Not Scare Us (Yet)'. Climatic Change 77: pp. 103-20.

Weber, Elke U. and Paul C. Stern. 2011. 'Public Understanding of Climate Change in the United States'. American Psychologist 66 (4): pp. 315-28.

Wilkinson, T. Martin 2013. 'Nudging and Manipulation'. Political Studies 61: pp. 341-55.

Notes:

( ${ }^{1}$ ) For a helpful overview of CCC, see Moser (2010). For a comprehensive collection of research, see Moser and Dilling (2007a).

$\left(^{2}\right)$ This chapter takes its prime example of CCC to be a climate scientist addressing a lay public, but many instances of CCC have different speakers and auditors. On the importance of specifying precisely which kind of communicator is involved, see Keohane, Lane, and Oppenheimer (2014), which takes scientist communication with 'policy makers and attentive publics' as its target case.

$\left({ }^{3}\right)$ On citizens as lay judges of scientific claims, see Lane (2014).

( $\left.{ }^{4}\right)$ Harré (2012) focuses notably on the intrinsic value and reward of ethical action, an approach that resonates with that of Lane (2011).

$\left({ }^{5}\right)$ Judd et al. (2005: 899). 'Warmth' is understood here as a technical term relating to social intention. Compare the compatible political science hypothesis on CCC offered by Arthur Lupia (2013: 14051): 'the listener must perceive the speaker to have sufficiently common interests and the listener must perceive the speaker to have relative expertise'.

$\left.{ }^{6}{ }^{6}\right)$ This is the deeper moral of the thoughtful discussion by Martin Wilkinson (2013). While Wilkinson hazards the view that 'manipulation is intentionally and successfully influencing someone using methods that pervert choice' (Wilkinson 
2013: 347), he is also sensitive to the difficulty of articulating a complete definition independent of the audience's judgement.

${ }^{7}$ ) We also recognize that there are significant dissimilarities between Aristotle's context and our own, which we are unable to address owing to length restrictions.

$\left(^{8}\right)$ McCabe argues that Plato's objections have three different grounds: 'epistemological (rhetoric is based on no objective truth), ethical (rhetoric is selfdeceiving and thus bad for its practitioners), and political (rhetoric deceives others and damages the interests of those it addresses)' (McCabe 1994: 134-5).

$\left({ }^{9}\right)$ Fischhoff recognizes that 'persuasive communication' may be needed if nonpersuasive communication fails, but 'such advocacy comes at a price' and 'must be very effective to compensate for eroding scientists' status as trusted observers and reporters' (Fischhoff 2007: 7208).

$\left({ }^{10}\right)$ All passages from the Rhetoric are from Kennedy's translation (Aristotle 2006), unless otherwise noted.

$\left({ }^{11}\right)$ For discussion, see McCabe 1994: 142 and Irwin 1996: 143-4. Moser briefly mentions this passage and the relevance of Aristotle's Rhetoric for CCC (Moser 2010: 31, 37).

$\left.{ }^{12}\right)$ Here we disagree with Eugene Garver, who claims that '[e]xpertise and specialization are incompatible with citizenship' and that Aristotle's 'Rhetoric is about those aspects of human affairs for which there are no experts and for which everyone is assumed to have an opinion' (Garver 1994: 20-1). On the contrary, Aristotle was acutely aware of the need to communicate between some who know some things and others who do not (see Irwin 1996; Reeve 1996).

(13) Importantly, Aristotle did not believe that emotional appeals are necessarily irrational or impermissible, as some suggest (e.g. Sprute 1994). Rather, Aristotle thought emotions could aid deliberation and reflect rational judgements. His concern about emotional appeals related to their abuse. "The difficulty was not simply that judicial orators aroused emotions but that they aroused the wrong emotions, at the wrong times, and in the wrong ways. They appealed to emotions that drew upon irrelevant facts' (Garsten 2006: 123; cf. Cooper 1994).

$\left.{ }^{14}\right)$ Our Aristotelian approach has affinities with Agyeman et al. 2007; Regan 2007; Moser 2010: 41, and Schlosberg 2013.

$\left({ }^{15}\right)$ Hart and Nisbet (2012) note that certain audience predispositions-such as political partisanship_can affect whether specific audiences are motivated by localized messages. Their study suggests, for example, that Republicans in the United States may be more likely to support climate change mitigation when 
messages highlight effects on local communities rather than distant populations (Hart and Nisbet 2012: 715-17).

$\left.{ }^{16}\right)$ See $N E$ 1.2.4-8, where Aristotle identifies 'political science' as the 'highest ruling science' and argues that 'even the most honored capacities-generalship, household management, and rhetoric, for instance-are subordinate to it'. In Rhetoric 1.2.7, Aristotle describes rhetoric as an 'offshoot' [paraphues] of 'ethical studies (which is rightly called politics)'. For more on the relation between rhetoric and political science, see Cooper 1994, Irwin 1996, and Reeve 1996.

$\left({ }^{17}\right)$ For Allen, Aristotle's Rhetoric 'is neither a guide to manipulation nor a superficial manual of style, but rather a philosophically subtle analysis of how to generate trust in ways that preserve an audience's autonomy and accord with the norms of friendship' (Allen 2004: 141). As she puts it, the Rhetoric is in effect 'a treatise on talking to strangers' (143).

$\left.{ }^{18}\right)$ Compare this with the treatment of envy in Fiske and Dupree (2014), for whom those envied are judged to be superior rather than equal.

$\left({ }^{19}\right)$ Our Aristotelian approach fits with recommendations from Moser and Dilling (2007b: 498) and Markowitz and Shariff (2012: 245).

$\left({ }^{20}\right)$ Aristotle gives the example of dogs, who will not bite someone sitting down (Rhet. 2.3.6).

$\left({ }^{21}\right)$ One way to see the recommendation to the IPCC Working Group I in Keohane, Lane, and Oppenheimer (2014) is as asking scientists to sacrifice themselves, metaphorically speaking, by venturing subjective expert judgements in order to help citizens address their interests, in cases where evidence is insufficient to form objective judgements at the ordinarily expected levels of scientific credence. Compare the compatible recommendations for such cases in Jamieson and Hardy (2014).

$\left.{ }^{22}\right)$ We are grateful to Ezra Markowitz for helping us develop this point.

\section{Access brought to you by:}

